normal motion. The wound was healing well. A slight but not foul, discharge came from the abdominal wound, On the 20th the wound had firmly healed and the patient was up and about. On the 30th, on examination the whole of the rectum was found to be healed and the rectal wall was quite smooth all round. On June 9th the patient was discharged. The temperature for a week after the operation was 99.2 F. at night, otherwise it was normal throughout.

I have been unable to find any case quite similar to this one. Fæcal extravasation into the peritoneal cavity following perforation of the rectum is a rare condition and I know of no case that has been successfully treated by laparotomy. Some years ago I operated on a case of perforation of the rectum and bladder by a branch of a tree. The patient was a boy who whilst climbing a tree fell and staked himself. I did not see him until more than 12 hours after the accident and although I was able to sew up the bladder rent $i$ found his small intestine was also injured. He survived the operation about 24 hours. I attribute the recovery in the case related above mainly to the gauze packing and drainage and to our successful attempts to limit the contamination of the peritoneum to the parts immediately around the wound of the rectum. The suture of the rectal wound was very difficult. The stitches had to be put in as best one could and it was not at all certain that they were confined to the serous and muscular coats.

Half Moon-street, $W$.

\section{A SHORT NOTE ON THE USE OF LINEN SEWING-MACHINE THREAD FOR LIGATURES AND SUTURES.}

BY ARTHUR E. J. BARKER, F.R.C.S. ExG., SURGEON TO UNIVERSITY COLLEGE HOSPITAL.

THe question what ligatures and sutures it is best to employ in any given case is one which must often engage the attention of all surgeons of any large experience. mere glance at the list of materials employed at different times for the purposes in point must convince anyone that there is still a difference of opinion as to which is best. Most of us have, I suppose, in former times used the old hempen thread and silver wire, then catgut in all its forms, also kangaroo tendon and ox aorta, as well as silk of different kinds, silkworm-gut and horsehair, and, finally, celluloid hemp. Each has been shown to have its advantages but with each there is some drawback. The object of these few lines is to draw attention to a material certainly not new but which probably for its very commonness appears to have been but little used either as a Iigature or suture material and which after an experience of mearly two years I find to possess many merits. This is linen thread now made for the ubiquitous sewing-machine of the tailor and seamstress. I have used this now in a very large number of eases during the last two years, indeed, almost exclusively and $\mathrm{I}$ find it to possess the following good points. In the first place, it can be procured everywhere all over the world wherever there is a depôt for Singer's sewing. machines for which, I believe, it is specially spun. It is relatively very cheap. It can be easily sterilised by boiling in plain water and then stored in methylated spirit. It is enormously strong and ties a most uncompromising knot. It is easy to work with and runs through the eye of any suitable needle easily, having been spun with special care in order to travel evenly through the sewing-machine needle. I have ased several sizes and now limit these to three-viz., No. 40, which is as thick as need be desired for the abdominal wall or ligature of the larger arteries; No. 60, which is thinner but still very strong; and No. 90 , which is as fine as can be desired, say, for a suture of the intestine. I find it convenient to procure No. 40 as a white thread, No. 60 in red, and No. 90 in black. I have prepared it by simply boiling it for an hour in ordinary water and then keeping it in spirit A little of the dye comes out of the finer sizes in boiling but does not appear otherwise to alter the thread which can be boiled over and over again without rotting it.

One of the greatest tests of such a thread, to my mind, is an enterectomy or a gastro-enterostomy, and here I have given it a wide trial and have not yet known it to behave in any but the most satisfactory manner. Many of my patients are now going about with it in both stomach and intestine. But where it can be seen in the skin, as, for instance, in the long wound of a breast amputation, its non-irritating nature can be studied nhere it has not been tied too tight. It comes out at the end of 10 days or so just as it went in.

I cannot help thinking that to those who work in out-ofthe-way places and who often find it difficult to obtain the usual traditional materials of good quality this linen thread will prove a boon. It probably is not absorbed at all but appears to be none the worse for this. Cotton thread is not strong enough in my experience for surgical ligatures and, moreover, rots if much boiled. But this linen material is different and the flax fibre of which it is made is long and very smooth.

Harley-street, $w$.

\section{MENINGO-ENCEPHALOCELE.}

\section{BY EDGAR DU CANE, B.A, M.B. R. L.I.}

Ax infant, aged three and a half days, with a tumour in the occipital region, was brought to me by the midwife for operative treatment. The mother, aged 35 years, had had five healthy children at full term and one stillborn, the cause being unknown, and the present child was born after an interval of 10 years. No particular difficulty appeared to have occurred during labour and apart from the tumour the child appeared well-nourished and to have been born at full term. The tumour was found to be two-thirds the size of the child's head, globular in shape, and connected with the occipital region by a large circular peduncle covered with hair. The skin at the posterior portion was much thinner than elsewhere, being practically only membrane. Pulsation occurred when the child cried and besides the presence of fluid, evidenced by fluctuation, there were some solid contents. The connexion with the cranial cavity seemed to be between the centres of ossification of the occiput. I diagnosed the case as one of meningo-encephalocele and having explained to the parents the probability of a fatal termination whether an operation. was performed or not $I$ proceeded at their request to remove the tumour.

Having rendered the parts aseptic I aspirated four ounces of fluid and then, dissecting the skin back from the membranes, I separated each layer in the manner of treating a strangulated hernia and finally came upon the posterior portions of both occipital lobes. As these could not be returned into the cranial cavity I carefully excised the protruding portions which on examination proved to be immediately behind the angular gyrus. Bleeding vessels were tied or twisted, membranes were removed, and the edges of the membranes were stitched together; the skin was sutured and a firm pad of antiseptic gauze was applied. The child cried, took the breast, passed urine and defecated naturally, and presented no signs of paralysis and no convulsions. The wound healed rapidly without suppuration and only on the third day was there any rise of temperature, when it reached $100^{\circ} \mathrm{F}$., falling on the same night. After 14 days of uninterrupted progress the child had a convulsion and finally died $16 \frac{1}{2}$ days after the operation.

The post-mortem examination showed almost complete cicatrisation of the cerebral lesion, but the brain was adherent to the membranes and the latter to the operation wound. There were no pus and but little fluid in the cranial cavity nor was there any great distension of the ventricles. Apart from the cicatrisation extensive congestion was absent. My reasons for operating were as follows. 1. The disease, if left alone, is usually speedily fatal. ${ }^{1}$ 2. Dr. G. A. Wright of Manchester" says that "attempts have been made to excise the tumours with sufficient success to encourage further trials in selected cases." 3. Dr. D. Ferrier states that "though the occipital lobes are included in the visual centres it is nevertheless a remarkable fact that they can be injured, or cut off bodily, almost up to the parieto-occipital fissure on one or both sides simultaneously without the slightest appreciable impairment of vision." He further

1 Erichsen : ninth edition, vol. ii., p. 556.

2 Ashby and Wright: Diseases of Children, fourth edition, p. 571. a Functions of the Brain, second edition, p. $\Sigma 73$. 